\title{
Study of Emissivity of MOCVD Iridium Film with Different Topography
}

\author{
Shirui Yang, Xiaodong Yu, Chengwen Tan, Yandong Wang, Honglei Ma, Kexue Liu, Hongnian Cai \\ School of Materials Science and Engineering, \\ Beijing Institute of Technology, \\ No.5 South Zhongguancun Street, Haidian District, Beijing, 100081,
} P. R. China

\begin{abstract}
The emissivity of different topographies of iridium films which were obtained using $\operatorname{Ir}($ acac $) 3(1.216 \times 103$ $\mathrm{Pa})$ and hydrogen $(5.575 \times 104 \mathrm{~Pa})$ in a cold-wall reactor at atmospheric pressure was studied. The bigger size the grains are, the uneven topography is obtained, the higher the emissivity is. The bigger grain size is related to higher deposition temperature and turbulent flow in rapid deposition. The X-ray diffraction peaks indicate the only existence of metal iridium with highly crystalline structures. All the films show a (111) preferred orientation, which enhances with decreasing size grains and emissivity.
\end{abstract}

KEYWORDS: iridium, film, emissivity, Ir(acac)3

\section{INTRODUCTION}

Emissivity can be improved via the decoration of material surfaces by coating or films. High emissivity is widely required in airspace engine or high temperature furnace. Nowadays, the common coatings are made from zircon, $\mathrm{SiO}_{2}, \mathrm{Al}_{2} \mathrm{O}_{3}$ etc. oxides [1]. However, the adhesion of coatings to metallic substrates is not quite well, and the emissivity will lower down along with increased temperature. What's more, the work temperature of these coatings is only $800-1200^{\circ} \mathrm{C}$.

Compared to the above oxides, the noble metal iridium remarkably resists oxidization and a few types of corrosion even at high temperatures, making it a well-known protective film under space or other extreme environments [2]. Iridium can service long time above the temperature of $1200{ }^{\circ} \mathrm{C}$. Though the emissivity of metals will increase with increased temperature, the emissivity of metals is quite low.

Considering its expensive value and brittleness, the fabrication of iridium through chemical vapor deposition (CVD) process is found essential [3-10]. Among which, metallo-organic chemical vapor deposition (MOCVD) can be processed under much lower deposition temperatures, therefore aroused widespread concern. From a few iridium organic compound precursors studied previously, iridium(III) acetylacetonate $\left(\operatorname{Ir}(\mathrm{acac})_{3}\right)$ has become one of the most popular [11-15]. In addition, it is much easier to deposit coating/film on special shaped pieces.

Studies of iridium film deposition from $\operatorname{Ir}(\mathrm{acac})_{3}$ have already been performed. Yet, improvement of emissivity of high quality iridium films is still untouched. In this work, the iridium films with higher emissivity was fabricated. The relation between emissivity and microstructures of iridium MOCVD films deposited on polycrystalline molybdenum were investigated at hydrogen partial pressures of $5.575 \times 10^{4} \mathrm{~Pa}$ and deposition temperatures varied in the range $480{ }^{\circ} \mathrm{C}$ and $540{ }^{\circ} \mathrm{C}$.

\section{EXPERIMENTAL}

Iridium films were deposited through MOCVD in a cold-wall CVD reactor at atmospheric pressure. The apparatus is illustrated in Figure 1. Depositions were performed with argon as carrier gas and hydrogen as reducing gas. The deposition process has been reported in [].Iridium films were deposited using $\operatorname{Ir}(\mathrm{acac})_{3}$ at 480 and $540{ }^{\circ} \mathrm{C}$ with $1.216 \times 10^{3} \mathrm{~Pa} \operatorname{Ir}(\text { acac })_{3}$ partial pressure at $\mathrm{H}_{2}$ partial pressures of $5.575 \times 10^{4} \mathrm{~Pa}$ respectively.

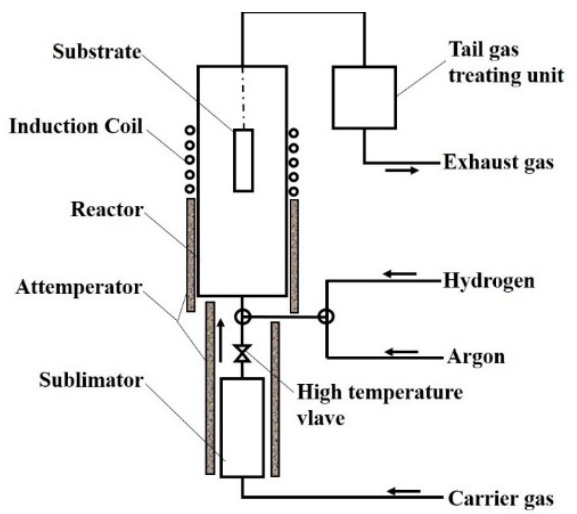

Figure 1. The setup of Ir film CVD apparatus.

All films were deposited onto $\Phi 6 \times 25$ polycrystalline molybdenum substrates, which had been annealed for $1 \mathrm{~h}$ at $1000{ }^{\circ} \mathrm{C}$ to remove internal stress. Before molybdenum is introduced into the reactor, the cylinder was sandblasted with $\mathrm{Al}_{2} \mathrm{O}_{3}$ and then ultrasonic cleaned with deionized water. The substrate was vertically suspended in the reactor and heated by a high-frequency induction heating (Xi'an Tianfeng, IGPS-30KW-200KHz). The temperature of the substrate was measured using an infrared thermometer (Xi'an Innocent, ATS). The flow rate of argon (99.999 wt. \%) and hydrogen (99.999 wt. \%) were determined using an electronic mass-flow meter (Beijing Sevenstar, D07).

Films microstructures were observed by scanning electron microscopy (SEM, Hitachi S-4800) and a $20 \mathrm{keV}$ accelerating voltage was used for the collection of SEM images. The film phase was analysed by X-ray diffraction spectroscopy (XRD, Panalytical X'Pert PRO MPD) and a copper source anode operating at $1.8 \mathrm{~kW}$ was used. The emissivity was analysed by thermal infrared imager (FLIR Altair). 


\section{RESULTS AND DISCUSSION}

The Ir film emissivity were tested and results are shown in Figure 2. Sample (a) was deposited at $540{ }^{\circ} \mathrm{C}$ while (b) at $480{ }^{\circ} \mathrm{C}$. Sample (b) has shown a regular emissivity of iridium at 0.08. Sample (a) has shown a much higher emissivity from 0.37 to 0.54 . Four typical regions were taken and studied, the according SEM images are shown in Figure 3.

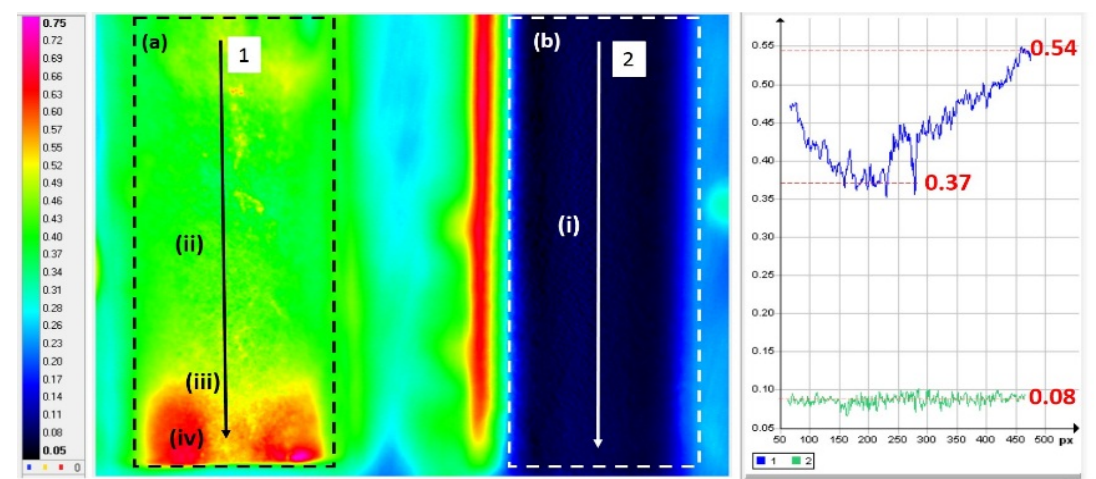

Figure 2. The emissivity of Ir film Sample (a) and (b).
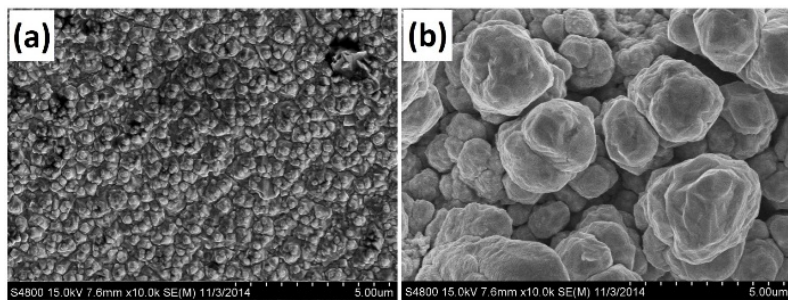

(c)
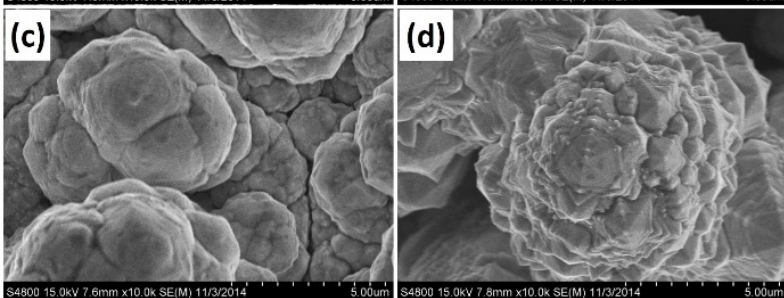

Figure 3. The SEM images of Ir film surfaces at region $i$ (a), ii (b), iii (c), and iv (d).

The surface state of materials will greatly affect the emissivity as reported. Evidently, the different areas of the Ir film surface show different topographies and emissivity. The bigger the grain size is, the uneven topography is, and the higher emissivity is obtained. It can be illustrated in Figure 4. On one hand, smaller grains will pack into even topography, as radiation comes in, then it will be easily reflect as shown in Figure 4 (a). On the other hand, as the uneven topography which is packed with big size grains, as radiation comes in, times diffuse reflections increased the chance to absorb radiation as shown in Figure 4 (b). In addition, the uneven topography increased the superficial area, this is another factor to increase emissivity. In the sketch of Figure 4, the reflection radiation is described into dash lines, for that from the minimize size of surfaces, there is also some loss of radiation energy.

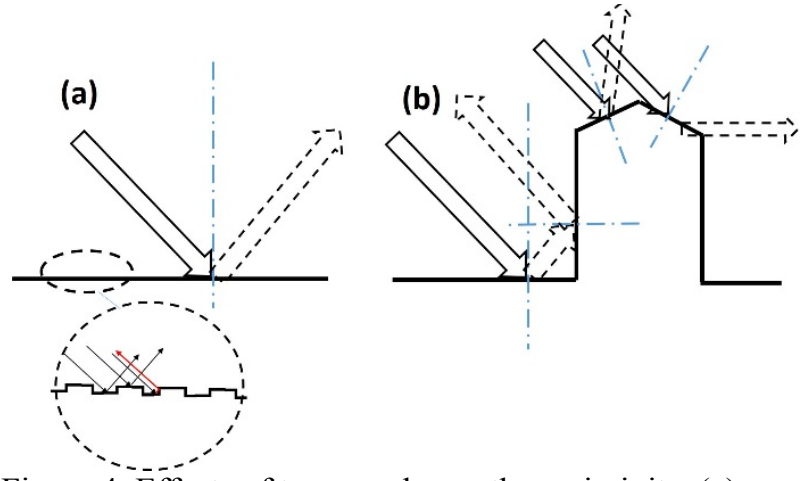

Figure 4. Effects of topography on the emissivity. (a) even topography with small grains, (b) uneven topography with bigger grains.

At the experimental conditions applied, the increase in grain size can be explained through the nucleation process. The nucleation rate is described in Eq. 9.

where $\mathrm{K}$ is the proportionality factor, is nucleation energy, and is activation energy of diffusion. Eq. 9 shows that the nucleation rate is controlled by two factors: the energy in the system, and the diffusion ability of atoms. Generally speaking, grain size depends on nucleation and nuclei growth processes. In nuclei growth process, grain size depends on the deposition temperature. In nuclei growth process, grain size increases with the increased deposition temperature in most situations, which is due to the activation of the diffusion of atoms. Therefore, the films got bigger grains at $540{ }^{\circ} \mathrm{C}$ (Sample (a)) than $480{ }^{\circ} \mathrm{C}$ (Sample (a)).

In Sample (a), the deposition temperature is even at $540{ }^{\circ} \mathrm{C}$. Therefore, temperature is not the effect factor. At the bottom of substrate, the flow around is turbulent. This leads to an increased supply of precursor. In the deposition at $540{ }^{\circ} \mathrm{C}$, the supply of $\operatorname{Ir}(\mathrm{acac})_{3}$ is not enough from the kinetics control, the closer to the precursor direction, the faster grow will be, and bigger size grains will fabricated. Compared to the deposition at $480{ }^{\circ} \mathrm{C}$, the 
deposition is kinetics control, the precursor supply is sufficient from every region of the substrate, therefore, the grain growth is even.

XRD data of polycrystalline iridium film regions of $i$, ii, iii, and iv are presented in Figure 8. Along with the decreased emissivities, the width of the X-ray diffraction peak is increasing evidently accordingly. According to Scherrer equation:

$$
D_{\mathrm{hkl}}=\mathrm{K} \lambda /\left(B_{\mathrm{hkl}} \cos \theta\right)
$$

where $D_{\mathrm{hkl}}$ is the crystallite size in the direction perpendicular to the lattice planes, hkl are the Miller indices of the planes being analysed, $\mathrm{K}$ is a numerical factor frequently referred to as the crystallite-shape factor, $\lambda$ is the wavelength of the X-rays, $B_{\mathrm{hkl}}$ is the width (full-width at half-maximum) of the X-ray diffraction peak in radians and $\theta$ is the Bragg angle. [48, 49]. The increased $B_{\mathrm{hkl}}$ reflects the decreased grain size. Therefore, the grain size decreased with the increased emissivities of iridium films, which is also illustrated in Figure 6 and 7.

The diffraction peaks also indicate the only existence of metal iridium. The high signal-to-noise suggests that the films are crystalline. Along with the increased emissivities, the ratio of $I_{(200)}$ over $I_{(111)}$ is increased from $\sim 0.36$ at region $\mathrm{i}$ to $\sim 0.44$ at region iv. These values indicate that the as-deposited films show a preferred (111) orientation (the $I_{(200)}$ over $I_{(111)}$ is 0.6 from the standard PDF card). What's more, then intensities of other crystal faces over $I_{(111)}$ are also weaker than that from standard PDF card. However, the intensities of other crystal faces over $I_{(111)}$ is increased with increased emissivity, such as $I_{(220)}$ over $I_{(111)}$ increases from 0.28 of region i to 0.53 of region iv. This indicates that the dominance of PO (111) decreased with the film increasing emissivities, and this appeared to a more free growth during deposition, which grains with bigger size and serious uneven topography were obtained.

Aaltonen et al. also reported that the preference of a (111) orientation was due to the relatively low surface energy of this orientation [40]. The total share of (111) has increased from 0.37 of region $i$ to 0.48 of region iv. The increase in surface energy, causes the increasing inclination of iridium bond to the film surface, while leading to the increase of the iridium bonds to better bound atoms, thus, the growth mode is inclined to change from Stranski-Krastanov or Volmer-Weber mode to Frank-van der Merwe mode [52]. In other words, once planar growth surface becomes established, subsequent atoms tend more to gather into bulges than to continue planar growth.

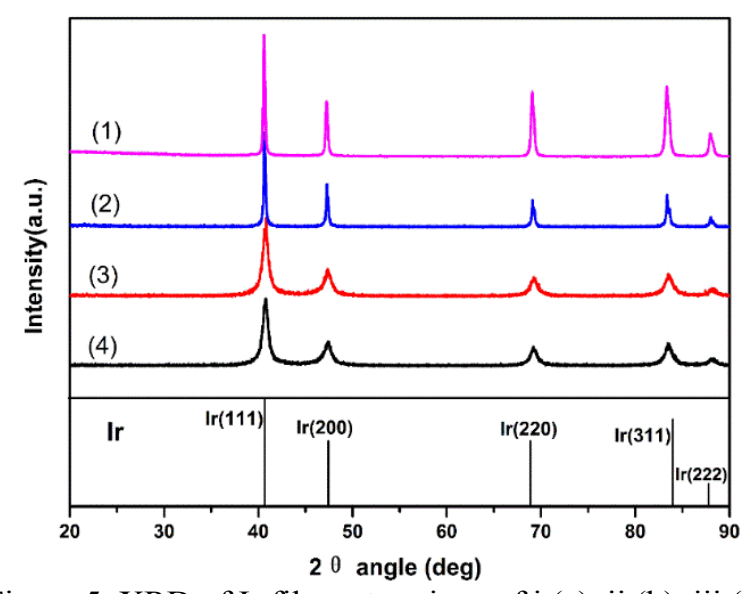

Figure 5. XRD of Ir films at regions of i (a), ii (b), iii (c), and iv (d).

\section{CONCLUSIONS}

The emissivity of different topographies of iridium films which were obtained using $\operatorname{Ir}(\mathrm{acac})_{3}\left(1.216 \times 10^{3} \mathrm{~Pa}\right)$ and hydrogen $\left(5.575 \times 10^{4} \mathrm{~Pa}\right)$ in a cold-wall reactor at atmospheric pressure was studied. At deposition temperatures $480{ }^{\circ} \mathrm{C}$, even topography with small grains were fabricated, and the emissivity is 0.08 . While at $540{ }^{\circ} \mathrm{C}$, uneven topography with bigger grains were fabricated, and the emissivity increased to $0.37-0.54$ according to different topographies.

The bigger size the grains are, the uneven topography is obtained, the higher the emissivity is. The bigger grain size is related to higher deposition temperature and turbulent flow at non-kinetic region.

The X-ray diffraction peaks indicate the only existence of metal iridium. The high signal-to-noise suggests that the films are crystalline. All the films show a (111) preference orientation, which enhances with decreasing size grains and emissivity.

\section{REFERENCES}

[1] Dierk-Frank, Fritz S, Andreas Z. Coated filmused for thermal insulation, electronic applications, noise absorption or membranes [P]. DE, 19537821, 1977-04-17

[2] Tuffias. R., Kaplan. R., Williams. B., Fortini. A., in AIAA, Space Programs and Technologies Conference, Huntsville, AL.

[3] Chen. Y. L. et al., Deposition of iridium thin films using new IrI CVD precursors. Chem. Vapor Depos. 8, 17-20 (2002).

[4] Hämäläinen. J. et al., (MeCp) Ir (CHD) and molecular oxygen as precursors in atomic layer deposition of iridium, J. Mat. Chem. 20, 7669-7675 (2010).

[5] Hoke, J. B., Stern, E. W. \& Murray, H. Low-temperature vapour deposition of high-purity iridium coatings from cyclooctadiene complexes of iridium. Synthesis of a novel liquid iridium chemica vapour deposition precursor. J. Mater. Chem. 1, 551-554 (1991).

[6] Lee. I. S. et al., Formation of nano iridium oxide: material properties and neural cell culture, Thin Solid Films 475, 332-336 (2005).

[7] Sun. Y. M. et al., Precursor chemistry and film growth with (methylcyclopentadienyl) (1,5-cyclooctadiene)iridium. J. Vac. Sci. Technol. A 18(1): 10-16 (2000).

[8] Bahlawane. N., Kohse-Höinghaus. K., Premkumar. P. A., Lenoble. D., Advances in the deposition chemistry of metal-containing thin films using gas phase processes, Chem. Sci. 3, 929-941 (2012).

[9] Igumenov. I. K., Gelfond. N. V., Morozova. N. B., Nizard. H., Overview of Coating Growth Mechanisms in MOCVD Processes 
as Observed in Pt Group Metals. Chem. Vapor Depos. 13, 633-637 (2007).

[10] Ivanovskii. A. L., Platinum group metal nitrides and carbides: synthesis, properties and simulation, Russ. Chem. Rev. 78, 303-318 (2009).

[11] Baklanova. N., Morozova. N., Kriventsov. V., Titov. A., Synthesis and microstructure of iridium coatings on carbon fibers. Carbon 56, 243-254 (2013).

[12] Derouane. E., Baker. R., Dumesic. J., Sherwood. R., Direct observation of wetting and spreading of iridium particles on graphite. J. Catal. 69, 101-110 (1981).

[13] Escard. J., Leclere. C., Contour. J., The state of supported irdium in a hydrazine decomposition catalyst. J. Catal. 29, 31-39 (1973).

[14] Gelfond. N. et al., An XPS study of the composition of iridium films obtained by MO CVD. Surf. Sci. 275, 323-331 (1992).

[15] Gelfond. N. et al., Structure of Ir and Ir-A12O3 coatings obtained by chemical vapor deposition in the presence of oxygen, J. struct. Chem. 51, 82-91 (2010). 